\title{
SHARED COMMUNICATIONS: VOLUME II. IN-DEPTH SYSTEMS RESEARCH
}

Tykey Truett (truettlf@ornl.gov)

Edmond Chin-Ping Chang

September 2004

Prepared for the

Federal Transit Administration

U.S. Department of Transportation Washington, D.C. 20590

Prepared by the

Center for Transportation Analysis

Oak Ridge National Laboratory

Oak Ridge, Tennessee 37831

Managed by UT-Battelle, LLC

For the U.S. Department of Energy

Under Contract No. DE-AC05-00OR22725 



\section{CONTENTS}

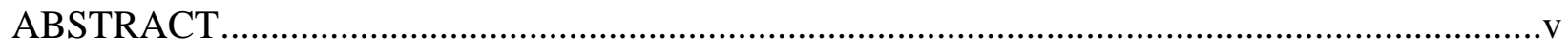

ACKNOWLEDGEMENTS ........................................................................................... vii

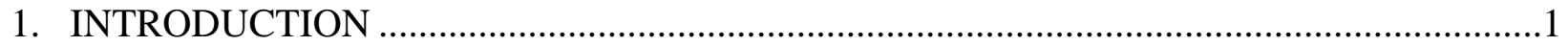

2. SHARED TELECOMMUNICATION INFRASTRUCTURE ............................................5

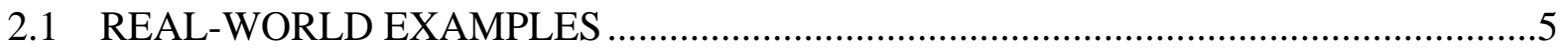

2.2 LESSONS LEARNED FROM THE SHARING EXPERIENCES .............................9

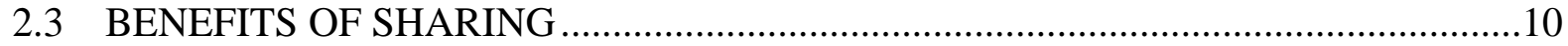

2.4 OPPORTUNITIES FOR ADDITIONAL APPLICATIONS .......................................10

2.5 INSTITUTIONAL ISSUES AND OTHER BARRIERS …........................................ 10

2.6 REFERENCES AND SOURCE MATERIALS .......................................................10

3. SHARED INFORMATION/DATA, TECHNOLOGIES, AND SOFTWARE.....................13

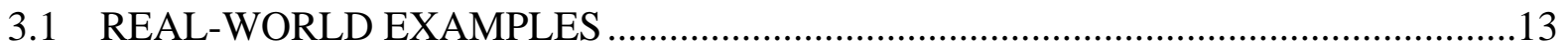

3.2 LESSONS LEARNED FROM THE SHARING EXPERIENCES ..............................17

3.3 BENEFITS OF SHARING ................................................................................. 17

3.4 OPPORTUNITIES FOR ADDITIONAL APPLICATIONS ..................................18

3.5 INSTITUTIONAL ISSUES AND OTHER BARRIERS ….....................................18

3.6 REFERENCES AND SOURCE MATERIALS .................................................18

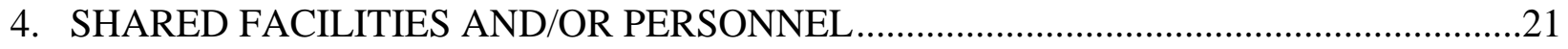

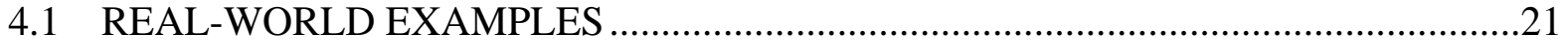

4.2 LESSONS LEARNED FROM THE SHARING EXPERIENCES .............................26

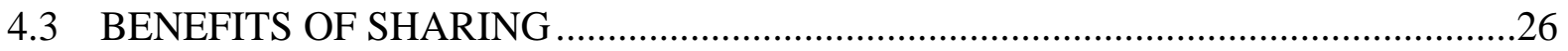

4.4 OPPORTUNITIES FOR ADDITIONAL APPLICATIONS........................................26

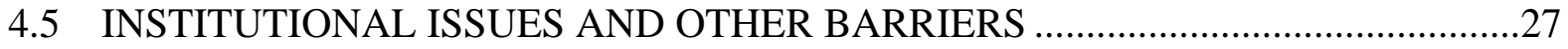

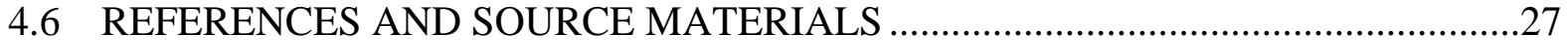

5. SUMMARY AND RECOMMENDATIONS...............................................................29

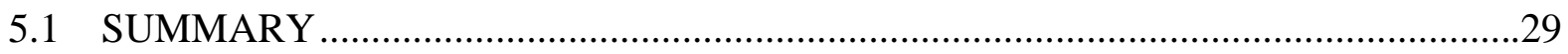

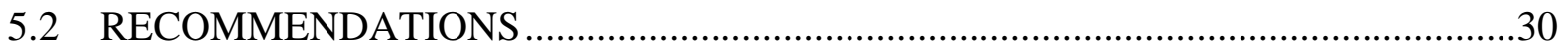

APPENDIX A: ACRONYMS AND ABBREVIATIONS …................................................33 



\begin{abstract}
This report is the second of two documents that examine the literature for actual examples of organizations and agencies that share communications resources. While the primary emphasis is on rural, intelligent transportation system (ITS) communications involving transit, examples will not be limited to rural activities, nor to ITS implementation, nor even to transit. In addition, the term “communication” will be broadly applied to include all information resources.

The first document of this series, Shared Communications: Volume I. A Summary and Literature Review, defines the meaning of the term "shared communication resources" and provides many examples of agencies that share resources. This document, Shared

Communications: Volume II. In-Depth Systems Research, reviews attributes that contributed to successful applications of the sharing communication resources concept. A few examples of each type of communication sharing are provided. Based on the issues and best practice realworld examples, recommendations for potential usage and recommended approaches for field operational tests are provided.
\end{abstract}





\section{ACKNOWLEDGEMENTS}

The authors would like to express their appreciation to the Office of Mobility Innovation (TRI11), Federal Transit Administration (FTA), and to the ITS Joint Program Office, U.S. Department of Transportation, for support of this study. 



\section{INTRODUCTION}

Appropriate, accurate, and reliable communication is the key ingredient of a successful Intelligent Transportation System (ITS). For rural ITS transit applications, however, there is a scarcity of communication infrastructure. This absence of physical components hinders the implementation of ITS applications in a rural setting. Sharing communication infrastructure, sharing information/data, sharing personnel and sharing the associated costs - are useful strategies to employ when planning a rural ITS application.

This document is the second volume is a set that describes the state-of-the-art of shared communications resources. The first volume, Shared Communications: Volume I. A Summary and Literature Review, ${ }^{1}$ provided an extensive listing of examples of shared resources. Based on this literature search, sites were chosen for more in-depth review in order to derive a set of lessons learned on how to successfully share resources.

The literature review concluded with the following observations:

- The most frequently shared communication resources are information/data resources,

- Telecommunications infrastructure and technologies are the next most frequently shared resources,

- When resources are successfully shared, all parties benefit,

- A few unsuccessful attempts to share resources have been recorded, along with lessons learned,

- Impediments to sharing include security issues, concerns over system availability and reliability, service quality and performance, and institutional barriers,

- Advantages of sharing include financial benefits to agencies from using shared resources and benefits to the public in terms of congestion mitigation, information transfer (e.g., traveler information systems), mobility (e.g., welfare-to-work paratransit), and safety (e.g., speed of incident response, incident avoidance),

- Technology-based solutions exist to address technology-based concerns, and

- Institutional issues can be addressed through leadership, enhanced knowledge and skills, open communication, responsiveness, and attractive pricing structures.

Figure 1 shows the distribution of sites that were noted in Volume I as examples of shared communication. Table 1 provides a list of sites that have received an in-depth analysis of their specific shared resource experiences. The sharing experiences of these sites are explained more fully in Sections 2-4 of this document.

\footnotetext{
${ }^{1}$ Franzese, Oscar, Tykey Truett, Edmond Chin-Ping Chang, Shared Communications: Volume I. A Summary and Literature Review, ORNL/TM-2004/198, Oak Ridge National Laboratory, Oak Ridge, Tennessee, September 2004.
} 


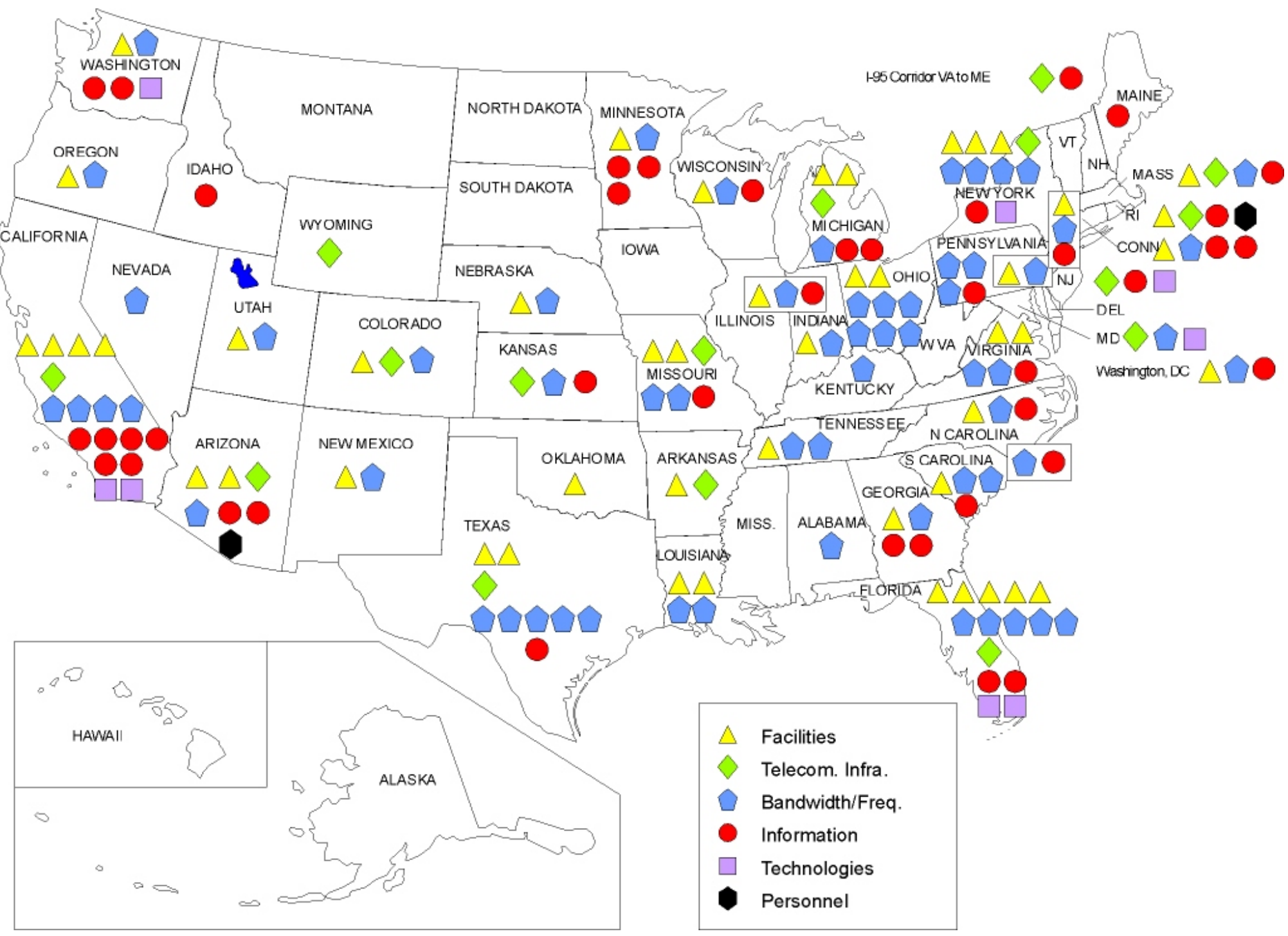

Figure 1. Sites that represent shared communication resources. 


\begin{tabular}{|c|c|c|c|c|}
\hline \multicolumn{5}{|c|}{ Table 1. Sites Examined in this Study for Examples of Shared Communication Resources } \\
\hline Site & Service & $\begin{array}{c}\text { Geographical/political } \\
\text { boundaries }\end{array}$ & Resources shared & Application \\
\hline $\begin{array}{l}\text { Florida, Northeast Florida } \\
\text { Regional Planning } \\
\text { Council }\end{array}$ & $\begin{array}{l}\text { Shared radio tower space and } \\
\text { bandwidth/frequencies between } \\
\text { county government and human } \\
\text { services agencies }\end{array}$ & $\begin{array}{l}\text { Six counties in northeast } \\
\text { Florida }\end{array}$ & $\begin{array}{l}\text { - Communication } \\
\text { infrastructure }\end{array}$ & Rural \\
\hline $\begin{array}{l}\text { Virginia, Resource } \\
\text { Sharing Program }\end{array}$ & $\begin{array}{l}\text { Cellular towers; fiber optic } \\
\text { cable; cellular service }\end{array}$ & $\begin{array}{l}\text { Six counties in northern } \\
\text { Virginia }\end{array}$ & $\begin{array}{l}\text { - Communication } \\
\text { infrastructure }\end{array}$ & $\begin{array}{l}\text { Rural, travel } \\
\text { management }\end{array}$ \\
\hline $\begin{array}{l}\text { City of Los Angeles: } \\
\text { Transit Priority System }\end{array}$ & $\begin{array}{l}\text { Transit priority and bus location } \\
\text { service }\end{array}$ & Los Angeles, California & $\begin{array}{l}\text { - Communication } \\
\text { infrastructure }\end{array}$ & $\begin{array}{l}\text { Travel, } \\
\text { traffic, transit }\end{array}$ \\
\hline $\begin{array}{l}\text { Florida, Rural Florida } \\
\text { ITS Project }\end{array}$ & $\begin{array}{l}\text { Software to coordinate and } \\
\text { integrate transportation needs } \\
\text { among human service agencies }\end{array}$ & Six counties in Florida & $\begin{array}{l}\text { - Information/data, } \\
\text { technology, software }\end{array}$ & Rural, ITS \\
\hline I-95 Corridor Coalition & $\begin{array}{l}\text { Integrated incident management } \\
\text { and regional information } \\
\text { service }\end{array}$ & $\begin{array}{l}17 \text { eastern states along the } \\
\text { I-95 corridor }\end{array}$ & $\begin{array}{l}\text { - Information/data, } \\
\text { technology, software }\end{array}$ & $\begin{array}{l}\text { ITS, travel } \\
\text { management }\end{array}$ \\
\hline $\begin{array}{l}\text { Rogue Valley } \\
\text { Transportation District \& } \\
\text { Valley Lift, Oregon }\end{array}$ & $\begin{array}{l}\text { Operations software and } \\
\text { geographic information system }\end{array}$ & $\begin{array}{l}\text { Five counties in southwest } \\
\text { Oregon }\end{array}$ & $\begin{array}{l}\text { - Information/data, } \\
\text { technology, software }\end{array}$ & $\begin{array}{l}\text { ITS, } \\
\text { coordination, } \\
\text { transit }\end{array}$ \\
\hline $\begin{array}{l}\text { Houston TranStar: } \\
\text { Resource Sharing }\end{array}$ & $\begin{array}{l}\text { Coordinated emergency } \\
\text { management }\end{array}$ & $\begin{array}{l}\text { Houston, Harris County, } \\
\text { Texas }\end{array}$ & $\begin{array}{ll}\text { - Information/data } \\
\text { technology, software } \\
\text { - Facilities, personnel, } \\
\text { development }\end{array}$ & $\begin{array}{l}\text { Travel, } \\
\text { transit, } \\
\text { emergency, } \\
\text { public safety }\end{array}$ \\
\hline $\begin{array}{l}\text { Minnesota GuideStar: } \\
\text { Shared Operations }\end{array}$ & $\begin{array}{l}\text { Integrated and virtual traffic } \\
\text { control center }\end{array}$ & $\begin{array}{l}\text { Mn/DOT, MSP, University } \\
\text { of Minnesota, U.S. DOT }\end{array}$ & $\begin{array}{l}\text { - Information/data } \\
\text { technology, software } \\
\text { - Facilities, personnel, } \\
\text { development }\end{array}$ & $\begin{array}{l}\text { Travel, } \\
\text { transit, } \\
\text { emergency, } \\
\text { public safety }\end{array}$ \\
\hline $\begin{array}{l}\text { CapWIN: Capital } \\
\text { Wireless Integrated } \\
\text { Network }\end{array}$ & $\begin{array}{l}\text { Integrated incident and } \\
\text { emergency response }\end{array}$ & $\begin{array}{l}\text { Maryland, Virginia, and } \\
\text { District of Columbia }\end{array}$ & $\begin{array}{ll}\text { - } & \text { Communication } \\
\text { infrastructure } \\
\text { - } & \text { Information/data } \\
\text { technology, software } \\
\text { - } & \text { Facilities, personnel, } \\
\text { development }\end{array}$ & $\begin{array}{l}\text { Travel, } \\
\text { transit, } \\
\text { emergency, } \\
\text { public safety }\end{array}$ \\
\hline
\end{tabular}


These in-depth studies are categorized on the basis of the resource that is being shared. In some instances, more than one resource is shared; however, the site is discussed only under its primary category. The resource categories are as follows:

- Section 2: Shared telecommunication infrastructure (including roadway right-of-way, bandwidth and frequency, and other components),

- Section 3: Shared information/data, technologies, and software, and

- Section 4: Shared facilities, personnel, and development.

Each of these categories is described more fully in the first volume of this series. For each category, two or more real-world examples (i.e., the in-depth study) provide insights on the actual sharing experiences. The following headings are used to describe the in-depth study sites:

- In a nutshell: brief description of the geographic location of the site, agencies involved, services provided, and funding resources;

- Goals: a description of the goals that the sharing application was intended to address;

- Approach: the approach that was taken to plan, implement, and operate the sharing process;

- Resources shared: an explanation of how this site and participating agencies shared the resource being examined;

- Current status: the current status of the real-world application;

- Cost information: insofar as is possible, cost information is supplied for implementation and operation; and

- Key contacts.

Finally, for each sharing category, the following information has been synthesized based on the real-world examples:

- Lessons learned from the sharing experiences,

- Benefits of sharing,

- Opportunities for additional applications,

- Institutional issues and other barriers, and

- Reference and source materials. 


\section{SHARED TELECOMMUNICATION INFRASTRUCTURE}

In this section, shared telecommunication infrastructure is defined to include towers and other wireless infrastructure, wireline (coaxial cable, fiber optic, copper) and conduit, cameras and closed circuit television (CCTV), highway advisory radio (HAR), variable message signs (VMS), spare parts, system documentation, local area networks (LANs) and other networks, and the roadside right-of-way. This section also includes interoperability capability (e.g., police, fire, and bus drivers sharing a bandwidth or frequency).

The Federal Highway Administration (FHWA) has compiled a table that lists the status of fiber optics or wireless communication on interstate highways or other freeways. In the comments section of the FHWA table are many examples of resource sharing. Some examples of sharing include Rhode Island, which obtained two conduits for state use in exchange for right-of-way usage. On the other hand, Pennsylvania law does not allow resource sharing on controlled access right-of-way and there is no fiber optics or wireless communication.

\subsection{REAL-WORLD EXAMPLES}

Three examples of infrastructure sharing are provided below. The first example illustrates how six counties (Baker, Clay, Flagler, Nassau, Putnam, and St. Johns) in northeast Florida use telecommunication infrastructure to improve transportation services for the transportation disadvantaged. The second example describes how the Virginia DOT (VDOT) Northern Virginia District Staff (six counties), VDOT Central Office, cellular tower companies, cellular carriers, and the Army Corps of Engineers get together to develop fiber optic telecommunications infrastructure and services to support the free cellular services for call boxes. The third example describes how the city of Los Angeles Department of Transportation (LADOT), in collaboration with the Los Angeles County Metropolitan Transportation Authority (MTA), and the cities of Beverly Hills and Santa Monica, successfully implemented an advanced Transit Priority System (TPS) and real-time bus location project for improved rapid bus services along two major transit corridors in downtown Los Angeles. 


\section{FLORIDA: NORTHEAST FLORIDA REGIONAL PLANNING COUNCIL}

\section{In a nutshell:}

Site: Six counties (Baker, Clay, Flagler, Nassau, Putnam, and St. Johns) in northeast Florida

Agencies involved: Northeast Florida Regional Planning Council (NEFRPC), Commission for the Transportation Disadvantaged (CTD), and various county governments

Services provided: Transportation services for the transportation disadvantaged

Funding sources: State of Florida; counties

\section{Goals:}

As the designated official planning agency for the six counties named above, to coordinate resources to reduce expenses for the human services agencies involved.

\section{Approach:}

No formal plan; information was gathered from interviews with each of the Community Transportation Coordinators in the counties to include in the annual report for the CTD. Publishing information on shared infrastructure encouraged the other counties to provide similar services.

\section{Resources shared:}

- $\quad$ Radio tower space (Clay, Flagler, and Putnam counties)

- Bandwidth/frequency (Clay County) for service and emergency calls

- Vehicle parking areas shared, building space leased cheaply, and utilities provided

\section{Current status:}

Ongoing

\section{Cost information:}

There was no cost attached to gathering and compiling the information. The values of the shared tower space and radio frequency were not estimated.

\section{Key contacts:}

Steven Jones, Senior Regional Planner, NEFRPC

(904) 279-0880X115

SJones@nefrpc.org 


\section{VIRGINIA: RESOURCE SHARING PROGRAM}

\section{In a nutshell:}

Site: Northern Virginia

Agencies involved: VDOT Northern Virginia District Staff (six counties), VDOT Central Office, cellular tower companies, cellular carriers, Army Corps of Engineers

Services provided: fiber optic telecommunications infrastructure and services; free cellular services for call boxes

Funding sources: $\$ 70,000$ in-kind hardware and services for each tower; cellular service in exchange for placing advertisements on call boxes.

\section{Goals:}

As part of Virginia's Smart Travel Program, these projects improve service delivery, enhance traffic operations, reduce travel delays, and make highways safer.

\section{Approach:}

VDOT entered into agreements with cellular tower companies for access and use of VDOT right-of-way in exchange for about $\$ 70,000$ of in-kind telecommunications-related hardware and services. VDOT attempted to secure partnership agreements with cellular carriers to provide free cellular service for being allowed to place their sponsorship logo on the call boxes. VDOT also signed a resource sharing contract with the Army Corps of Engineers (COE) for fiber optic communications infrastructure.

\section{Resources shared:}

Telecommunications infrastructure (cellular towers; fiber optic cable); cellular service

\section{Current status:}

As of October 2002, VDOT had received infrastructure sharing privileges that includes 10 traffic cameras, 20 cellular call boxes, one HAR station, one relay station and antenna for the radio, and two variable message signs located on ramps to serve as truck rollover warning signals. All of this is along 100 miles of interstate highway in northern Virginia.

There was an attempt to negotiate free cellular service for the call boxes along the Dulles Toll Road in exchange for placing logos on the call boxes. This did not work out because there were too many cell companies with too many demands concerning the logos. The call boxes are there, but VDOT pays for the cellular service.

Finally, the Army COE is providing additional fiber optic cable to connect much of the existing VDOT cables; in exchange, VDOT will provide access to COE for capacity on the existing cable.

\section{Cost information:}

There are no cost data available.

\section{Key contacts:}

Jimmy Chu, VDOT, Transportation Engineer

(703) 383-2600

Chu_TF@VDOT.state.va.us 


\title{
CITY OF LOS ANGELES: COORDINATED TRANSIT PRIORITY SYSTEM
}

\author{
In a nutshell: \\ Site: City of Los Angeles (2 major downtown transit corridors) \\ Agencies involved: LADOT, in collaboration with the Los Angeles County MTA, and cities of \\ Beverly Hills and Santa Monica. \\ Service provided: Transit priority and real-time bus location through existing traffic signal \\ system infrastructure \\ Funding sources: U.S. DOT, LADOT, Los Angeles County MTA
}

\section{Goal:}

The city of Los Angeles implemented an advanced TPS for buses along two major transit corridors in the Los Angeles Region to improve transit times and to project arrival times for waiting passengers. The system was shared with emergency vehicles.

\section{Approach:}

The Los Angeles Bureau of Transportation Design and Automated Traffic Surveillance and Control (ATSAC) is responsible for traffic design, signal timing, and ATSAC implementation. The TPS project is a critical element of the Metro Rapid Bus Demonstration Program that was jointly developed by LADOT and MTA. The initial phase of the Metro Rapid Bus was deployed on June 24, 2000, when the Metro Red Line subway was extended to the North Hollywood Stations in the San Fernando Valley. The purpose of the Metro Rapid Bus Demonstration Program is to offer rail-type frequent and high quality transit services connecting the terminus of the Red Line to major destinations in the outlining areas. The TPS project serves to improve the on-time performance of the Metro Rapid Bus by adjusting the signal timing at intersections for buses as their approach is detected. The TPS is also used to provide real-time next bus arrival information to passengers waiting at bus stations and assist bus fleet management by recording the travel time for each bus run. The Metro Rapid Bus program features limited stops and new low-floor clean-air buses.

\section{Resources shared:}

The TPS project involves adjusting timing of traffic signal and collecting real-time bus location information from both traffic signal systems and transit buses on two of the most heavily traveled transit corridors in Los Angeles: Ventura Boulevard and Wilshire/Whittier Boulevards. The Ventura Boulevard Corridor, consisting of 88 signalized intersections and 16 miles of roadway, connects the Metro Red Line Station at Universal City to the Warner Center, a major commercial and business center in the West San Fernando Valley. The Wilshire/Whittier Boulevard Corridor, consisting of 123 signalized intersections and 14 miles of roadway, traverses through the central part of the Los Angeles Basin and connects East Los Angeles with the Central Business District, and the Cities of Beverly Hills and Santa Monica. Separate communication infrastructure for the jurisdictions is both economically impractical and politically infeasible.

The TPS Project also includes control of dynamic passenger information signs at selected bus shelters along the Metro Rapid Bus routes. These highly visible light-emitting diode (LED) signs inform passengers of the estimated arrival times of the next Metro Rapid bus. The arrival time information is computed by the system based on the actual speed of the bus and is accurate to within one minute. LADOT staff also developed the sophisticated algorithm that calculates the arrival time. Each signalized intersection in the project area is equipped with loop detectors that serve as Automatic Vehicle Identification (AVI) sensors. These sensors embedded in the pavement receive a radio-frequency code from a small transponder installed on the underside of a vehicle. Buses equipped with unique 
transponders will be detected when traveling over the loop detectors. These loops are connected to a sensor unit within the traffic signal controller at each intersection, which transmits the bus identification number to the TPM computer in the City's ATSAC Center at City Hall East for tracking and schedule comparison. Once the bus identification and location are received, the computer makes a determination of the need for traffic signal priority. If the bus is early or ahead of the scheduled headway, no traffic signal priority treatment is provided. However, if the bus is late or beyond the scheduled headway, then the downstream traffic signal controller will provide signal priority to help the bus catch up with the scheduled headway. In addition, real-time data links from the MTA dispatch center to the ATSAC center is used to obtain the daily bus assignment for schedule comparison.

\section{Current status:}

The system is currently fully operational. Based on the before-and-after travel time studies, this study indicated that an average of $27-33 \%$ travel time or $33-36 \%$ delay saving due to the integrated TPS.

\section{Cost Information:}

MTA estimated that a \$3.3 million annual operating cost saving for the MTA not counting the added benefit of travel time saving to the Rapid Bus passengers. The TPS cost almost \$3 million to install along both Ventura Boulevard and Wilshire/Whittier Boulevards, including the cost of the software development. A total of 211 signalized intersections are outfitted with the TPS, at an average intersection cost of $\$ 15,000$ per intersection. With an anticipated project life cycle of 10 years, the relative benefitscost ratio is more than eleven-to-one.

\section{Key contacts:}

Frances T. Banerjee, General Manager

City of Los Angeles, Department of Transportation

221, N. Figueroa Street, Los Angeles, CA 90012 USA

TEL: 213-580-1177 Fax: 213-580-1188

e-mail: ladot@dot.lacity.org

\subsection{LESSONS LEARNED FROM THE SHARING EXPERIENCES}

The most important lesson learned from the NEFRPC experience was that agencies and organizations are more willing to share their telecommunications infrastructure when they receive credit for the sharing. That is, the annual report gave acknowledgement for sharing practices; the publicity encouraged additional participation and sharing.

The northern Virginia resource sharing experiences led to lessons concerning how to work with contractors of other companies. For example, when VDOT made agreements with a cellular company for a product or service, the cellular company would make arrangements with a different contractor to actually provide the product or service. This contractor might not be aware of the engineering and safety regulations of the state. There was a considerable amount of paperwork needed to fulfill requirements. The state was also responsible for inspecting the work, which implied that the state had to allocate resources to track the service and check up on the work. Working with companies that didn't understand the state's standards created additional work for the state; however, the problems were overcome and the results worth the effort. 
The Los Angeles TPS showed that an investment in signal timing can result in a payback period of about one year, plus increase passenger convenience. It also showed minimal impact on cross street traffic.

\subsection{BENEFITS OF SHARING}

Publishing the information collected from the six counties served by the NEFRPC encouraged the other counties to provide similar services.

The northern Virginia resource sharing experience provided benefits to the state organization by providing services and goods that the state did not have the money to obtain. It also provided a benefit in time; that is, there was no need to go through their two-year budget process for allocating funds, since no funds were needed. It provided a public benefit.

The city of Los Angeles' TSP system represents the successful sharing of physical infrastructure to achieve rapid ITS system implementation and deployment from the perspective of both travel/traffic management and transit agencies.

\subsection{OPPORTUNITIES FOR ADDITIONAL APPLICATIONS}

There is an opportunity for joint transportation management, public safety, and security applications.

\subsection{INSTITUTIONAL ISSUES AND OTHER BARRIERS}

There are no barriers to sharing the NEFRPC data.

The Northern Virginia District staff had to change some policies for getting work done. In the past, when they wanted something on "their" interstates, they just went ahead and did the work. However, with the resource sharing issue, they had to go through the county permit process. That is, the District covered six counties; when a cell tower was needed in the different counties, they had to get permission. They also held public meetings to avoid citizen protests regarding the towers (i.e., the "not in my backyard” reaction).

Barriers to a TPS are objections to non-transit travelers who might feel that they had been delayed by the signal, which gives priority to the bus.

\subsection{REFERENCES AND SOURCE MATERIALS}

Bard, E., and K. Barron, “The Virginia State Department of Transportation's Approach to Public-Private Partnerships for ITS,” in Proceedings of the 8th ITS America. Meeting: Transportation Technology for Tomorrow, Detroit, Michigan, 1998.

Chu, Jimmy, Transportation Engineer, Northern Virginia District, (703) 383-2600, Personal communication, October 18, 2002. 
Federal Highway Administration, "Resource Sharing: State-by-State Status Report, July 2002 Update,” http://www.ghwa.dot.gov/realestate/utilsr.htm .

Florida Commission for the Transportation Disadvantaged, 2002. “2001 Annual Performance Report - Major Accomplishments, Executive Summary,” “2001 Annual Performance Report - Program Performance,” "2001 Annual Performance Report - Statewide Analysis and Summary,” http://www11.myflorida.com/ctd/a\%20web\%20page\%20layout/3\%20Program\%20Infor mation/1\%20ProgramInformation.htm .

Lopez, E.M., “Supporting ITS Through Public Private Partnerships: Virginia's Statewide Fiber Optic Resource Sharing Program,” in Proceedings of the 69th Annual Meeting of the Institute of Transportation Engineers: Transportation Frontiers for the Next Millennium, Las Vegas, Nevada, Aug 1-4, 1999.

Steve Jones, Northeast Florida Regional Planning Council, (904) 279-0880, Personal communication, August 12, 2002.

Tang, Amy, Summary of 1999 Activities, Northern Virginia District (NOVA) Smart Travel Program, http://www.virginiadot.org/infoservice/resources/smart-nova-summaryprogram-act.pdf , 1999.

“Transit Priority System - Evaluation Report,” Department of Transportation, City of Los Angeles. April 2001. 



\section{SHARED INFORMATION/DATA, TECHNOLOGIES, AND SOFTWARE}

Shared data can be raw or processed. Shared software might include, for example, a geographic information system (GIS), which could be shared among several regional agencies. Shared information also includes sharing media, such as a web page or spots on public media such as television, radio, newsprint, or other advertisement venues. Some of the more widely used ITS technologies include automatic passenger counts, automatic vehicle location (AVL) capabilities, real-time traveler information, fare cards (or other electronic payment systems), global positioning satellite (GPS) technologies, emergency alarms and Mayday systems, mobile data terminals, traffic signal preferential treatment, digital communications, automatic destination signs, and stop annunciators.

\subsection{REAL-WORLD EXAMPLES}

Reviews are presented below to illustrate information and technology sharing. One example, involving six counties in Northeast Florida (not the same six counties described in Section 2.1), illustrates some limitations on technology sharing when the use of the technology involves a major change in the way individuals do their jobs. Another example explores technology sharing that involves multiple states along the I-95 corridor. The final example concerns coordination and partnership among five counties in southwest Oregon. 


\section{FLORIDA: RURAL FLORIDA ITS PROJECT}

\section{In a nutshell:}

Site: Six counties (Alachua, Flagler, Levy, Marion, Putnam, and St. Johns) in northeast Florida Agencies involved: CTD and various county Community Transportation Coordinators Services provided: Transportation services for the transportation disadvantaged Funding Sources: State of Florida

\section{Goals:}

Sharing ITS technology for coordinating demand-response trips from a regional perspective. The purpose of introducing ITS advanced technologies to the rural counties was to improve efficiency; in addition, the counties were to share similar technologies and, therefore, improve service to the transportation disadvantaged community.

\section{Approach:}

In 1997, with a grant from the Federal Transit Administration (FTA), CTD distributed funds to three counties in northeast Florida (Flagler, Putnam, and St. Johns) to demonstrate the effects of ITS technologies in rural applications. In 1999-2000, two additional Community Transportation Coordinators (three more counties) were added.

\section{Resources shared:}

The plan was to share the software package RouteLogic in all counties except Putnam. Putnam County previously used and continues to use a proprietary software package. Integration of the Putnam County software with the RouteLogic package was never attempted or planned.

\section{Current status:}

In 2004, four counties continue to share information successfully. The county coordinators, however, still call or fax their inter-jurisdictional requests, rather than depending on the software.

\section{Cost information:}

FTA: $\$ 400,000$

CTD: $\$ 50,000$

\section{Key contacts:}

Mary Constiner Freeman Karen Somerset

Transportation Disadvantaged Specialist, $\quad$ Assistant Director, CTD

CTD

(850) 410-5702

(850) 410-5701

Mary.Constiner@dot.state.fl.us

Karen.Somerset@dot.state.fl.us 


\section{I-95 CORRIDOR COALITION: INTEGRATED SYSTEM FOR CORRIDOR OPERATIONS MANAGEMENT (ISCOM)}

\section{In a nutshell:}

Site: States along the I-95 corridor

Agencies involved: U.S., State, and local DOTs; toll, transit, rail, freight, and transportation authorities, other agencies

Services provided: Integrated operations and shared data

Funding sources: I-95 Coalition members, Federal funds

\section{Goals:}

To use a GIS to link a database management system, a set of analytical applications tools, and high-quality web-accessible presentation and mapping capabilities; to knit together local and state pockets of information to form a comprehensive regional information picture.

\section{Approach:}

The I-95 Corridor Coalition began in 1993. The ISCOM concept was initiated in 2001. The I-95 Corridor Coalition is an alliance of agencies and organizations that makes decisions on issues of a common interest. The original approach was to define options for end products, evaluate potential data sources and system design options, determine potential bottlenecks, and present these findings to the Coalition for a decision on how to proceed.

\section{Resources shared:}

Technology - GIS (plus, the GIS managers in individual states working together); Information - local, state, and metropolitan datasets; multimodal electronic toll and fare payments; traveler information

\section{Current status:}

Geographic membership currently includes boundaries of 17 states and Canada; using a widearea-network connecting Traffic Management Centers, members exchange and share information on incidents. Also, supported via GIS sharing is an extended traveler information system connecting both urban and rural areas. The coalition also supports (1) a commercial vehicle safety and productivity initiative and (2) shared electronic tolls and fares.

\section{Cost information:}

Initial cost of ISCOM planning was \$200,000. Updated cost information is unavailable.

\section{Key contacts:}

Kevin Tierney, Cambridge Systematics

617-354-0167

KFT@camsys.com 


\section{ROGUE VALLEY TRANSPORTATION DISTRICT \& VALLEY LIFT}

\section{In a nutshell:}

Site: Five counties in southwest Oregon

Agencies involved: U.S., State, and local agencies

Services provided: Integrated operations and software

Funding sources: Federal, state, and local funds

\section{Goals:}

To use ITS technologies to centralize and coordinate scheduling, dispatching, and reporting operations for five county governments, multiple social service agencies, and transit operators.

\section{Approach:}

The "right" people were brought together to plan the coordination system. An assessment of current capabilities was compared against agency needs five years out. A primary objective was for transportation people to understand social service people and vice versa. Funding was acquired from multiple sources. The Rogue Valley Transportation District (RVTD) took the lead for developing the operational plan.

\section{Resources shared:}

The various agencies and organizations shared an operations software package, a GIS, and an Internet website; these technologies fully integrated all social programs with RVTD's various transportation-related programs. In addition, a rideshare program was also coordinated.

\section{Current status:}

The RVTD currently operates fixed-route buses, ADA demand-response vehicles, the centralized call center, and many special programs aimed at educating people, including children, about the advantages of using transportation modes other than the single-occupant vehicle.

\section{Cost information:}

Cost recovery based on rider fares is about 22\% of the total operating costs for the RVTD.

\section{Key contacts:}

Yvonne Fletes, Financial Manager/Interim General Manager

541-779-5821

y.fletes@rvtd.org 


\subsection{LESSONS LEARNED FROM THE SHARING EXPERIENCES}

In the Rural Florida ITS project, the technology was supplied and the personnel received training in its use. Because they did not fully trust the software, they instead relied on the "old" methodology (telephones and faxes). They felt comfortable using the technology with which they were familiar. The lesson learned is that acquiring trust in new technology takes time, as well as training.

The I-95 ISCOM project has launched several successful programs, and expects to continue coordinating solutions for transportation needs along this busy corridor. Because so many states are involved, programming budget funds must be carefully coordinated.

The RVTD experience showed the importance of communication between it is for transportation and human services staff.

\subsection{BENEFITS OF SHARING}

Although there was greater cooperation and communication among the six counties in the Rural Florida ITS project after they received new technology for sharing, they did not receive the full benefits of the new technology because they did not trust it completely (i.e., they still relied on phones and faxes). The benefits of bringing rural Community Transportation Coordinators together to plan for implementation of new ITS technologies had some non-ITS benefits. Many staff had little experience with sophisticated software applications, but believed that the efficiency and productivity would be improved. They believed that there would be obstacles, but that they would surmount them. This may have had an impact on their cooperative efforts.

For the I-95 ISCOM project, the benefits are as follows:

- States can improve policies by looking/planning regionally.

- The impact of operational policies in one state affects all the states in the corridor; thus, looking at operational issues for the entire region will identify weaknesses/strengths in a plan.

- The traffic from Maine to Florida can be impacted by an incident on I-95. Sharing incident information via the information exchange network helps travelers determine alternative routes in order to alleviate congestion.

- The GIS allows what-if planning.

- Travelers have much more comprehensive information available.

The RVTD has provided more efficient services for all agencies by integrating existing programs through ITS operational software and a GIS package. 


\subsection{OPPORTUNITIES FOR ADDITIONAL APPLICATIONS}

It has been shown that coordinated system hardware and software deployment benefits state budgets, helps travelers, and enables better planning. Research and development collaboration along other major travel corridors could identify additional applications.

\subsection{INSTITUTIONAL ISSUES AND OTHER BARRIERS}

Barriers include the following:

- Establishing differential fares,

- Convincing agencies of the cost advantage,

- Billing social service agencies for trips,

- Addressing feelings of competition by private providers,

- Resolving agency turf issues and other concerns,

- Ensuring availability of wheelchair accessible vehicles,

- Overcoming the negative image of transit,

- Easing people's fears of riding the bus,

- Timing issues,

- Funding issues (i.e., coordination of equitable payments for particular projects and planning projects into the various state budgets),

- Problems with respect to hardware procurement, training database conversion,

- Decisions regarding benefits of off-the-shelf software packages vs a proprietary program,

- Software integration (e.g., incorporating programs for Medicare processing),

- Difficulty in capturing data,

- Jurisdictional issues,

- Technical issues involving integration of multiple GISs (i.e., all states use different GISs),

- Technical issues involving ownership and maintenance of software and hardware, and

- Ensuring that personnel in each state work together cohesively.

\subsection{REFERENCES AND SOURCE MATERIALS}

Baniak, John, and Nancy Ross, The Development and Evolution of the I-95 Corridor Coalition: Think Regionally, Act Locally, no date.

Crain \& Associates, Handbook for Rural Flexroute Implementation: The Santee Wateree Regional Transportation Authority Experience, Doc. No. 20-0200, for Easter Seals Project ACTION, http://www.projectaction.org/newdlist/cat7docs.htm, no date.

Minton, Eric, “On the Road Again,” Planning, American Planning Association, September 1999, pp. 4-8. 
Federal Highway Administration/Federal Transit Administration, Advanced Public

Transportation Systems Deployment in the United States, FTA-MA-26-7007-99-1, DOTVNTSC-FTA-99-1, 1999.

Federal Highway Administration/Federal Transit Administration, Small Urban and Rural Advanced Public Transportation Systems, FTA-TRI-11-99-28, FHWA-OP-99-040, 1999.

Federal Highway Administration/Federal Transit Administration, Technology in Rural Transit: Linking People with their Community, FTA-MA-99-0356-01-1, FHWA-OP-02-028, 2002.

"I-95 Corridor Coalition Integrated System for Corridor Operations and Management (ISCOM),” [slide presentation], November, 2000.

"Integrated System for Corridor Operations Management (ISCOM, Draft Year 8 Project Statement and Work Plan,” http://www.i95coalition.org/projects/PMISCOM_Project_Statement_draft.html .

Northeast Florida Regional Planning Council, “About Us,” and "Programs/Regional Transportation,” http://www.nefrpc.org .

TD Connector, A Quarterly Newsletter of the Commission for the Transportation Disadvantaged, Spring 2002. Vol. 8, Issues 1 and 2, printed from http://www11.myflorida.com/ctd/a\%20Web\%20Page\%20layout/2\%20Program\%20News /d\%200\%20newsletter.htm .

Tierney, Kevin, Cambridge Systematics, 617-354-0167, personal communication, October 17, 2002. 



\section{SHARED FACILITIES AND/OR PERSONNEL}

Savings can also result from sharing of facilities (e.g., Traffic Management Centers, buildings, and broadcasting equipment within buildings) and personnel. This section also includes examples of sharing system development responsibilities.

\subsection{REAL-WORLD EXAMPLES}

The following examples provide information about successful facility sharing. Houston TranStar's partner agencies are responsible for the planning, design, operations and maintenance of transportation operations and traffic emergency management operations within the Greater Houston Area. Minnesota's DOT (Mn/DOT) and the Minnesota State Patrol (MSP) are implementing a network of nine Transportation Operation and Communication Centers (TOCCs) through the "Virtual Transportation Operations Center" (VTOC) concept to serve both rural and the smaller urban areas outside the Twin Cities metro area. Operating agencies in Maryland, Virginia, and District of Columbia for the joint development of the Capital Wireless Integrated Network (CapWIN) provide firefighters, police, transportation officials and other authorized emergency personnel with wireless access to multiple government data sources during critical incidents. Improved access to information will help these "first responders" and public safety officials make vital public safety-related decisions for improved security applications.

\section{HOUSTON TRANSTAR: RESOURCE SHARING PROGRAM}

\section{In a nutshell:}

Site: Houston Metro Area, Texas

Agencies involved: Harris County, Texas DOT, Houston METRO, and City of Houston.

Services provided: coordination of ITS programs, Traffic Emergency Management Systems, enforcement efforts, and transit operational functions.

Funding sources: Each agency contributes to the annual operating budget of the center on a prorated basis relative to their occupancy and utilization of building components.

\section{Goals:}

Houston TranStar's agencies are responsible for the planning, design, operations, and maintenance of transportation operations and traffic emergency management operations within the Greater Houston Area.

\section{Approach:}

The TranStar service area encompasses 5,436 square miles with a population of 4.0 million. TranStar's agencies are responsible for the management of a variety of freeways and arterial street systems. Components managed by TranStar include:

- A 160-mile Freeway Management System, out of a projected 300 miles,

- Freeway and arterial street incident management,

- Ramp metering at 128 ramps ,

- 316 CCTV freeway cameras, 
- 154 dynamic message signs,

- Highway advisory radio (12 fixed sites and 1 portable site),

- 94.4 miles of barrier-separated reversible high-occupancy vehicle (HOV) lanes, with an additional 6.6 miles of diamond lanes on the I-10 freeway,

- A regional traffic signal system of 2,800 signals,

- ITS programs,

- Emergency management operations, and

- Flood alert system/roadway weather information systems.

\section{Resources shared:}

Houston TranStar is a multi-governmental facility and truly integrated in terms of the systems, personnel, and work functions that reach across jurisdictional boundaries. The unique feature of TranStar is its seamless integration of agency personnel and responsibilities. Unlike other Transportation Management Centers, Houston TranStar has combined transportation and emergency management specialists. This integrated structure creates an effective environment in terms of responsiveness, elimination of administrative and boundary constraints and pooling of finances, personnel and equipment resources. For each participating agency, TranStar provides the opportunity to aggressively focus on implementing transportation practices and emergency management response and recovery functions.

\section{Current status:}

Houston TranStar is located in a 52,000 square foot TMC specially constructed to accommodate the many high technology components and integrated multi-agency specialists. The TranStar Building includes a network of shared facilities, including central control operations room, communications room, telephone switch room, briefing and Emergency Operations Center, and three floors of offices for staff of the participating agencies. The building also contains viewing areas where the public and news media can learn more about the Center's operation and monitor information during special and emergency events.

\section{Cost information:}

The cost for the Houston TranStar Center was \$13.5 million, which consisted of design, construction, and systems integration. It is estimated that $\$ 1$ million per year can be saved through coordinated, integrated operations.

\section{Key contacts:}

Andy Mao, Harris County, County Traffic Engineer

TEL: 713-755-6465

e-Mail: AMao@eng.co.harris.tx.us

Houston TranStar

6922 Old Katy Rd.

Houston, TX 77024 USA

TEL: 713-881-3000 FAX: 713-881-3006

website: http://www.houstontranstar.org/ 


\section{MINNESOTA GUIDESTAR: SHARED OPERATIONS}

\section{In a nutshell:}

Site: Serving rural and the smaller urban areas outside the Minneapolis/St. Paul, Twin Cities metropolitan area.

Agencies involved: Minnesota DOT Office of Traffic Engineering and Intelligent Transportation Systems in partnership with the FHWA, U.S. DOT, University of Minnesota, numerous other public and private partners, and ITS Minnesota, the state chapter of ITS America.

Service provided: Integrated statewide communication and transportation operations network.

Funding Sources: U.S. DOT, Minnesota DOT, and Minnesota State Patrol (MSP).

\section{Goals:}

Mn/DOT and the MSP are implementing a network of nine TOCCs. The goal of these TOCC centers is to establish an integrated statewide communication and transportation operations network serving rural and the smaller urban areas outside the Twin Cities metro area.

\section{Approach:}

The individual TOCCs will act as regional centers for 24-hour incident and emergency response, multiagency dispatching and fleet management, interagency communications, collection and dissemination of road conditions and closures, traffic management, and, potentially, integrated transit operations. TOCCs are geographically distributed around Minnesota with Virginia, Baxter and Thief River Falls in the north, Detroit Lakes, St. Cloud and Duluth in the center part of the state, and Marshall, Mankato, and Rochester located in the south.

The TOCCs are being built around a framework of proactive interagency cooperation, updated facilities and technologies, and enhanced voice and data communications to improve Mn/DOT and MSP operational effectiveness and to improve the overall safety and efficiency of the transportation system in the state of Minnesota. TOCC facilities have been or are being upgraded in all nine centers. By summer of 2002, seven center facilities will have been completed. The new facilities include radio consoles, workstations, uninterrupted power supplies, and digital radio and telephone recorders. TOCCs are being equipped with new tools to improve operator effectiveness and service to travelers. The first is Intergraph's computer-aided dispatching (CAD). The second is the Minnesota Condition Acquisition and Reporting System, which is Minnesota's version of the pooled fund system developed by CRC, Inc. The third new system is the weather forecasts developed as a part of the Minnesota Road Weather Information System.

\section{Resources shared:}

Services and performance expectations were documented in the Mn/DOT and MSP Memorandum of Understanding (MOU) signed in early 2002. Based on the MOU and a corresponding generic service agreement, all services were expected to be fully functional by the fall of 2002 or when CAD was operational, whichever was later. The key to implementation of the TOCCs is data and voice communications. TOCC needs for wireless voice and data communication capacity and coverage have far outreached Mn/DOT's aging radio and analog microwave networks. A Comprehensive State Communications Network Plan was developed and used to guide upgrading the analog microwave network to a digital microwave network. This network will primarily serve center to vehicle communications. Key digital microwave corridors are being implemented as the first phase to replace the aged analog system. 
Some TOCCs are being equipped with the "Virtual Transportation Operations Center" (VTOC) software system developed by ADDCO, Inc. VTOC is being implemented, initially, only in the Duluth, St. Cloud, Rochester, and Mankato TOCCs. VTOC is fully operational in Duluth, and should be fully operational in the other three centers. In-vehicle systems are being implemented to improve TOCC operator efficiency and reduce routine workload. Radio caller IDs are added to Mn/DOT maintenance fleet and identifying the caller on the radio console and CAD monitor. GPS and mobile data computers (MDC) are being added to MSP squad cars. The GPS will improve dispatching efficiency. The MDC is allowing troopers to directly access certain records and to perform low priority communications without assistance of TOCC operators. Radio IDs are operational and in use. MDCs were installed during the first half of 2002, and were operational by the end of the summer 2002. Data radio coverage is being developed in key corridors to support the mobile data computers. Additional communication voice radio infrastructure is being implemented to address differences between Mn/DOT and MSP boundaries.

\section{Current Status:}

Minnesota Guidestar is the state's ITS program. Its mission is to research, test, and deploy advanced transportation technology to save lives, time, and money. Current Minnesota GuideStar initiatives include improving traveler information, improving safety at rail crossings, testing systems on vehicles to assist drivers, and creating statewide operations centers for managing the transportation system. TOCCs are intended to meet performance expectations relative to each of the services that they perform. These services, including interagency communications, multi-agency dispatching, traffic management, weather monitoring, road condition reporting, and others, are in various states of implementation.

\section{Cost information:}

Cost information was not available.

\section{Key contact:}

Tom Peters, TOCC Program Manager

$\mathrm{Mn} / \mathrm{DOT}$ Office of Traffic Engineering and ITS

Mail Stop 725 (OTE) Mail Stop 320 (ITS)

395 John Ireland Boulevard

St. Paul, Minnesota 55155-1899 USA

TEL: 651-282-2469

e-mail: guidestar@dot.state.mn.us

e-mail: tom.peters@dot.state.mn.us 


\section{CAPWIN: CAPITAL WIRELESS INTEGRATED NETWORK}

\section{In a nutshell:}

Site: Virginia, Maryland, and the District of Columbia

Agencies Involved: National Institute of Justice, Office of Science and Technology's Project AGILE, Maryland State Highway Administration, VDOT, the Public Safety Wireless Network, the U.S. Department of Justice's Office of Domestic Preparedness, U.S. DOT Center for Advanced Transportation Technology at the University of Maryland with support by George Mason University, University of Virginia, the International Association of Chiefs of Police and the International Association of Fire Chiefs. Services provided: integrated, wide-area wireless information network Funding sources: U.S. DOT, states of Maryland, Virginia, and District of Columbia

\section{Goals:}

(CapWIN is designed to provide firefighters, police, transportation officials, and other authorized emergency personnel with wireless access to multiple government data sources during critical incidents. Improved access to information will help these "first responders" and public safety officials make vital public safety-related decisions. The system was designed to eliminate the confusion that can plague responders currently hampered by incompatible communication gear and insufficient information. This project, once operational, will be the first interoperable wireless system to span multi-state government jurisdictions. The network will enable officials from more than 40 local, state, and federal agencies to communicate with each other in real time.

\section{Approach:}

On August 7, 2002, public safety and transportation agencies in Virginia, Maryland, and the District of Columbia decided to build a public safety data communications network for the Washington, D.C., area. "For the first time, the greater Washington, D.C., region will have a secure and powerful system that lets police, firefighters, transportation officials, and other responders communicate with each other rapidly during crises," said Chief Charles Samarra, chief of the Alexandria, Va., Police Department and chair of the CapWIN Executive Committee. "The strength of CapWIN is the partnerships that have developed and the sense that we have to work together for the greater good of our communities." Sen. George Allen (RVa.), who spearheaded congressional funding for CapWIN, said, "One important lesson we learned from September 11, 2001 is that we needed to do more to help our first responders communicate seamlessly and more effectively across jurisdictions and different systems.”

\section{Resources shared:}

Data and voice-based telecommunications infrastructure (cellular towers; fiber optic cable), cellular service, and jointed software development are shared.

\section{Current Status:}

CapWIN is designed for simplicity and ease of use. To better manage and coordinate multiple agencies responding to an incident, officials will communicate with each other on the network via an instant messaging application deployed on low cost, industry standard devices such as PCs, PDAs and dataenabled mobile phones. Authorized users will be able to set up response teams - restricted-access, highperformance chat rooms - to help handle unexpected events, such as natural disasters, traffic collisions, fires, or terrorist threats. A police officer responding to an automobile accident, for example, may communicate simultaneously with key personnel - including ambulance drivers, firefighters, and transportation response units, as well as the hazardous materials team and other special units. In addition, network users will be able to establish longer-term groups to stay in touch with each other during ongoing 
assignments - a criminal investigation, for example. Another advantage of the network is data access across jurisdictions in the DC/Maryland/Virginia region. Today, a police officer typically can only obtain information from his or her own department's records management system. CapWIN will provide a communication bridge to all participating agencies in the region, including jurisdictions throughout Virginia and Maryland.

\section{Costs information:}

Potentially, \$20 million has been saved over the scenario of all involved operating agencies developing their own systems and system upgrade projects.

\section{Key contacts:}

George Ake, UMD, Program Manger

University of Maryland

TEL: 301-403-4601 Fax: 301-403-4591

e-Mail: gake@wam.umd.edu

website: http://www.capwinproject.com/

\subsection{LESSONS LEARNED FROM THE SHARING EXPERIENCES}

Resource sharing of widespread applications requires the establishment of formal interagency agreement and/or MOUs, well-coordinated management structures, and operational budgets to be implemented successfully.

\subsection{BENEFITS OF SHARING}

Various Houston TranStar partner agencies were able to implement entire projects from planning and design to operations and maintenance for transportation operations and traffic emergency management operations within the greater Houston Area.

$\mathrm{Mn} / \mathrm{DOT}$ and the MSP were able to implement a network of nine TOCCs and serve both rural and smaller urban areas outside the Twin Cities metro area.

Implementing the CapWIN shared communication network will have minimal impact on the existing information and communication systems already in place at the CapWIN network operating agencies, but will significantly improve the incident response times during potential future natural and/or man-made disasters.

\subsection{OPPORTUNITIES FOR ADDITIONAL APPLICATIONS}

The feasible and sustainable ITS business model relies on the establishment of formal cooperative agreements among the major operating agencies. Once initial implementation can be demonstrated with success, the potential for additional applications can be endless. 


\subsection{INSTITUTIONAL ISSUES AND OTHER BARRIERS}

Coordinated system hardware and software deployment, as well as research and development collaboration along the major travel corridors are needed. Luckily, most major national priority corridors have developed or are in the process of developing regional or statewide system architectures to guide future ITS deployment. However, significant institutional issues still remain, such as budgetary constraints and procurement practices imposed on different operating agencies. Field Operational Test (FOT) type demonstration projects to lay out the necessary "Development Models," could demonstrate the recommended project development steps, and benefit-and-cost data will definitely improve future regional ITS system integration.

\subsection{REFERENCES AND SOURCE MATERIALS}

ITS America Advanced Rural Transportation Systems Committee, “Rural Intelligent Transportation Systems - an Environmental Scan,” Prepared for the Intelligent Transportation Society of America, December 2000.

Federal Transit Administration, U.S. Department of Transportation, "FY03 Strategic Business Plan,” http://franet.fta.dot.gov/10-7-02 , September 2002.

Mn/DOT Office of Traffic Engineering and ITS, Minnesota Department of Transportation, “TOCC Concept and Migration Plan,” February 2000.

“Memorandum of Understanding between Minnesota’s Department of Transportation (Mn/DOT) and the Minnesota Department of Public Safety - State Patrol (MSP) for Transportation Operation and Communication Centers (TOCCs),” November 2001. 



\section{SUMMARY AND RECOMMENDATIONS}

As summarized in the ITS America Advanced Rural Transportation Systems Committee Report, entitled: "Rural Intelligent Transportation Systems - an environmental scan," there are many fundamental challenges to achieve the long-term success of a rural ITS, including the availability of a viable infrastructure to deploy needed functionality. This needed basic infrastructure must be addressed over the next several years for the improved integration and increasing deployment of ITS.

Many early ITS development efforts have focused on ITS deployment projects in specific geographic coverage or application areas. In addition, the opportunities often rely on where the environment, funding, or institutional supports are available to accelerate these initiatives. However, greater challenges exist for the widespread ITS deployments in rural areas, due to the economic, institutional, or operational feasibility.

\subsection{SUMMARY}

Several key issues exist today for effective resource sharing and successful ITS deployment in both rural areas and in the smaller urban areas outside major metropolitan areas. The major practical issues that need to be addressed include:

- Feasible deployment models,

- Identification of necessary public and private roles,

- Identifiable marketing opportunities, and

- Accessibility of technologies.

\section{Feasible deployment models:}

It is not yet known whether there are any preferred models for the deployment of rural ITS which will influence either its technical or financial viability. For example, should the deployments be urban-centered, growing outward from initial deployments in metropolitan areas; or should they focus on deployment along the principal inter-urban corridors, which carry the majority of the individual and commercial travel that exists in rural areas? Alternatively, should they initially cover specific rural areas to respond to particular high-priority rural needs and problems? Similar questions exist from an application rather than a geographic perspective. A traveler information system may need to grow from an existing urban base to provide contiguous coverage for those travelers who begin their trip from an urban center, while a mayday system might be better developed from a rural base where the problems are greater and more clearly perceived by travelers. 


\section{Identification of necessary public and private roles:}

A second key area relates to the appropriate roles for the public and private sectors in rural ITS deployments. The Advanced Rural Transportation Systems Program Plan25 recognizes that the public sector has traditionally provided a common transportation infrastructure for private use, while the private sector competitively provides services for users, especially for users of automobiles or commercial vehicles. The plan notes that this allocation of roles is effective in matching needs with investments through market influences, and those competitive incentives in the private sector can lead to the rapid adoption of new technologies. In turn, the public sector dominates where the market does not respond well; for example, where the deployment of a common infrastructure with public benefits cannot adequately be captured by pricing or for highrisk activities, payoffs and penalties are best pooled by a large entity such as government.

\section{Identifiable marketing opportunities:}

Operating agencies need to define the limit of the private market opportunities with respect to rural ITS, and determine where, when, and how the public sector should provide assistance. Deployment efforts to date have not been of sufficient scale or scope to adequately determine the configuration of a rural ITS, how it should be deployed, and the appropriate roles for both the public and private sectors in implementing and sustaining it. An interesting example of this topic relates to cellular telephone coverage in rural areas. Cellular phones have been recognized to have value in the rural ITS community in the near-term. However, the cellular coverage in remote or mountainous areas is often spotty or non-existent; these are areas that likely represent regions where ITS applications are needed the most.

\section{Accessibility of technology:}

The fourth issue is the accessibility of technology by all users of the rural transportation system and the self-sustainability of rural ITS services. For example, several public sector transportation and public safety agencies became involved in the early development and deployment of rural mayday systems because of the compelling public interest in highway/traveler safety and increasing security considerations. These initiatives appear to have concluded with acknowledgment of the benefits, but questions of how the required in-vehicle devices will become broadly available to the traveler are coupled with a resignation that it would be inappropriate for the public sector to participate in this activity. With respect to selfsustainability, a number of public agencies have entered the rural traveler information arena with the belief that initial funding grants to the private sector will be sufficient to create selfsustaining businesses. When this promise has not appeared true over the relatively short duration of the early projects, the public sector has generally chosen not to wrestle with the challenging issue of long-term public subsidies.

\subsection{RECOMMENDATIONS}

Many ITS community leaders have recommended broadening the rural ITS model deployment. However, FOTs of shared communication and integration of rural ITS components will be far more challenging than in the metropolitan areas. On the other hand, the operational benefits and potential payoffs are likely to be high once the rural ITS system can be established. Various rural ITS infrastructure elements can be used to leverage more integrated deployment efforts. Any 
successful rural ITS deployment needs to overcome the integration over large areas, among multiple systems, and between established infrastructures; it will have to rely more on the private sector applications. The evaluation of a rural model deployment or FOT can help to address the various infrastructure and other deployment considerations and provide significant quantifiable benefits by identifying best practices in rural ITS deployment.

The concept of "Shared Communication and/or Resource" can be further defined into three different levels, which include "Level 1 - Shared telecommunication infrastructure" (including roadway right-of-way, bandwidth and frequency, and other components), "Level 2 - Shared information/data, technologies, and software," and "Level 3 - Shared facilities and/or personnel” as defined in this particular study.

Based on the findings of this study, it is recommended that an FOT of "Shared Communications and Resources" be conducted to assess the detailed benefit-and-cost issues for future rural ITS system implementation, since most existing projects did not measure these important performance measures.

The following characteristics of the recommended FOT are proposed:

- Coordinated transit service, improved transit safety, and enhanced security issues should remain the main theme of the recommended FOT and can address the concerns on feasible deployment models, needed public and private roles, identifiable marketing opportunities, and accessibility of ITS technologies.

- As required in the current USDOT ITS deployment efforts, the proposed FOT should focus on those areas that can provide technical assistance and the most payoff and that can move regions with low-level and medium-level ITS Integration into medium-level and high-level ITS Integration,

- Establishment of the regional ITS system architecture should form the basis to examine the validity of the proposed FOT. Shared communication projects should examine and maximize the interactions among various operating agencies located in close-proximity of the rural areas.

- The FOT should use proven ITS technologies, create a workable operating environment through collaboration, and encourage basic ITS infrastructure that can be economically deployed, easily operated, easily expanded, and adequately maintained. 



\section{APPENDIX A. ACRONYMS AND ABBREVIATIONS}

\begin{tabular}{|c|c|}
\hline ADA & Americans with Disabilities Act \\
\hline ATSAC & Automated Traffic Surveillance and Control \\
\hline AVI & Automatic Vehicle Identification \\
\hline AVL & Automatic Vehicle Location \\
\hline CAD & Computer-aided Dispatching \\
\hline CapWIN & Capital Wireless Integrated Network \\
\hline CCTV & Closed Circuit Television \\
\hline $\mathrm{COE}$ & Corps of Engineers \\
\hline CTD & Commission for the Transportation Disadvantaged \\
\hline DOT & Department of Transportation \\
\hline FHWA & Federal Highway Administration \\
\hline FOT & Field Operational Test \\
\hline FTA & Federal Transit Administration \\
\hline GIS & Geographic Information System \\
\hline GPS & Global Positioning Satellite \\
\hline HAR & Highway Advisory Radio \\
\hline $\mathrm{HOV}$ & High Occupancy Vehicle \\
\hline ISCOM & Integrated System for Corridor Operations Management \\
\hline ITS & Intelligent Transportation System \\
\hline LADOT & Los Angeles Department of Transportation \\
\hline LAN & Local Area Network \\
\hline LED & Light-Emitting Diode \\
\hline MDC & Mobile Data Computers \\
\hline MDT & Mobile Data Terminal \\
\hline $\mathrm{Mn} / \mathrm{DOT}$ & Minnesota Department of Transportation \\
\hline MOU & Memorandum of Understanding \\
\hline MSP & Minnesota State Police \\
\hline MTA & Metropolitan Transportation Authority \\
\hline NEFRPC & Northeast Florida Regional Planning Council \\
\hline ORNL & Oak Ridge National Laboratory \\
\hline RVTD & Rogue Valley Transportation District \\
\hline SWRTA & Santee Water Regional Transportation Authority \\
\hline TOCC & Transportation Operation and Communication Centers \\
\hline TPS & Transit Priority System \\
\hline VDOT & Virginia Department of Transportation \\
\hline VMS & Variable Message Signs \\
\hline VTOC & Virtual Transportation Operations Center \\
\hline
\end{tabular}

